\title{
A inadequação da destinação de recursos obtidos pelo MPT ao Fundo de Amparo ao Trabalhador e sua utilização em ações de política pública social $^{1}$
}

The inappropriate destination of MPT obtained resources to the Fund Support to the Employee and it's utilization in public social actions

\author{
Marina Silva Tramonte ${ }^{2}$ \\ Prof. Dr. Reginaldo Melhado ${ }^{3}$ \\ Dr. Heiler Ivens de Souza Natali. ${ }^{4}$
}

\begin{abstract}
Resumo
Desenvolve-se o tema da destinação de recursos provenientes de Termos de Ajuste de Conduta e condenações judiciais pelo Ministério Público do Trabalho como forma de promover ações de política pública social em face da inadequação de referida destinação ao fundo de amparo ao trabalhador. Tem por objetivo o estudo breve das formas de obtenção desses recursos, para posterior análise da inconveniência da destinação habitualmente utilizada pelo órgão ministerial ao FAT e novas roupagens que possibilitem a consecução das metas institucionais e dos objetivos e interesses tutelados pela Constituição da República Federativa do Brasil. Visa também a demonstrar a legitimidade do MPT para essa nova forma de destinação no cenário jurídico nacional. Jurisprudência de todo o país já vem demonstrando a tendência criativa do Ministério Público do Trabalho como agente de transformação social. A importância do tema está relacionada com a efetividade dos direitos sociais e, principalmente, com o verdadeiro sentido de justiça e reparação dos danos difusos, coletivos e individuais homogêneos em relação aos direitos juslaborais.
\end{abstract}

Palavras-chave: Destinação de Recursos; Termo de Ajuste de Conduta; Ação Civil Pública; Ministério Público do Trabalho; Fundo de Amparo ao Trabalhador.

1 Artigo científico desenvolvido a partir de Trabalho de Conclusão de Curso apresentado em junho/2011 na Universidade Estadual de Londrina.

2 Pós graduanda em direito e processo do trabalho pela Univesidade Anhanguera-Uniderp/LFG. Advogada. Graduada em Direito pela Universidade Estadual de Londrina no ano de 2011, fez estágio no Ministério Público do Trabalho, no Ministério Público Federal, na Promotoria da Infância e Juventude e na área trabalhista do escritório de aplicação de assuntos jurídicos da UEL.

3 Doutor em filosofia jurídica, moral e política - UB (Espanha), Juiz titular da 6a Vara do Trabalho de Londrina, Professor da Universidade Estadual de Londrina.

4 Procurador do Trabalho no Município de Londrina. 


\begin{abstract}
Discusses allocation of resources coming both from Terms of Conduct's Adjustement and from convictions by the Public Ministry of Work as a way of promoting social and public policy actions in light of the inappropriate destination to FAT - Fund Support to the employee.. It aims at the study of forms to obtain these resources, their usual destination by the ministerial body and new approaches to enable the achievement of institutional goals and interests sheltered by the Constitution of the Federative Republic of Brazil. Also, aims to demonstrate MPT legitimacy regarding the execution of those public policies in the national juridical scene. Jurisprudence across all country already show the creative tendency of the Public Ministry of Work as an social transformation enabler. The importance of this matter is related to the effectiveness of the social rights, and, mainly to the true meaning of justice and restitution of diffuse, collective and homogeneous individual damage to the labor rights.
\end{abstract}

Keywords: Resources allocation; Term of Conduct's Adjustement; Civil Action Public, Public Ministry of Work; Fund Support to the employee.

\title{
Introdução
}

As reparações das mais diversas espécies de danos tendem a ser monetizadas, transformadas em indenizações pecuniárias ou multas. O presente estudo tem o objetivo de demonstrar a inadequação da destinação dos recursos obtidos pelo Ministério Público do Trabalho - MPT, ao Fundo de Amparo do Trabalhador - FAT, bem como averiguar possibilidades de destinação para esses recursos de modo a abrir caminho para a adoção de verdadeiras ações de políticas públicas trabalhistas pelo próprio órgão ministerial.

Trata-se de tema relevante à defesa da cidadania e ordem social, conforme os preceitos instituídos pela Constituição da República Federativa do Brasil. O tema desperta dúvidas e incertezas com relação à sua aplicação e efetividade, pois envolve a tutela dos direitos difusos e coletivos trabalhistas, indisponíveis e responsáveis pela construção de uma sociedade livre, justa e solidária, conforme disposto em nossa Carta Constitucional.

Políticas Públicas, de acordo com a professora Maria Paula Dallari Bucci (2002, p. 241), são programas de ação governamental visando a coordenar os meios à disposição do Estado e as atividades privadas, para a realização de objetivos socialmente relevantes e politicamente determinados.

Em que pese essa legitimidade ser do Estado, também o Ministério Público está legitimado a executar ações de cunho social que visem a reparar os danos ocasionados, 
A inadequação da destinação de recursos obtidos pelo MPT ao Fundo de Amparo ao Trabalhador e a sua utilização em ações de política pública social

sendo verdadeiro promotor das políticas públicas constitucionalmente previstas, agindo como executor dessas medidas.

Assim, podemos dizer que políticas públicas são metas coletivas conscientes (ASSMAN, 2002 apud BUCCI, 2002, p. 241) e, portanto, um problema de todo o direito público, onde o Ministério Público tem suas raízes.

A presente pesquisa não tem como objetivo analisar os danos juslaborais sofridos pelos trabalhadores, mas, sim, a destinação dos recursos advindos das condenações judiciais e dos termos de compromisso, os quais serão utilizados pelo Ministério Público do Trabalho para a melhoria de vida do trabalhador e a reparação efetiva do dano causado.

Referidas medidas se tornam imprescindíveis na atualidade, posto que a globalização conferiu grande destaque aos danos difusos e coletivos, sendo necessária a criação de mecanismos que possibilitem a resolução de uma espécie de lide relativamente nova para o direito processual brasileiro, e que ainda traz em seu bojo inúmeras dúvidas que impedem sua plena execução.

Dessa maneira, o estudo em tela é pautado nas formas de reparação in natura dos danos trabalhistas, tendo por base as ações civis públicas e os termos de ajuste de conduta firmados pelo Ministério Público do Trabalho, bem como o estudo da destinação desses recursos a programas, instituições e ações sociais voltadas à comunidade lesada, de forma a auxiliar no desenvolvimento social e nas políticas públicas planejadas pelos governantes.

\section{Os meios de obtenção de recursos pelo MPT e a inadequação da destinação ao} Fundo de Amparo ao Trabalhador

Os principais meios de obtenção de recursos que o membro do MPT tem em mãos quando do seu exercício profissional são as verbas provenientes das condenações pecuniárias em sede ação civil pública e multas decorrentes de termos de ajuste de conduta firmados no bojo de inquéritos civis, ambas de grande monta, pois referem-se a parcelas de caráter pedagógico instituído às empresas que descumprem reiteradamente a legislação trabalhista.

A Ação Civil Pública visa a responsabilização judicial por danos e ameaças aos chamados direitos transindividuais, que abrangem os direitos difusos, coletivos e os individuais homogêneos. O Ministério Público é um dos principais legitimados à propositura 
dessa ação, que pode resultar, dentre outras soluções possíveis, em uma condenação pecuniária ou em um comando inibitório.

O Termo de Ajuste de Conduta (TAC), por sua vez, rotineiramente surge após a instauração de um Inquérito Civil ou de um procedimento preparatório por parte do MPT. O Inquérito Civil é instrumento constitucionalmente garantido ao órgão ministerial para a investigação e colheita de informações que resultem na instauração de uma ação judicial, no arquivamento do procedimento ou na firmatura de um TAC.

O TAC é medida de extrema importância no cenário jurídico atual, pois possibilita a eficácia que seria alcançada por meio de um efetivo provimento jurisdicional, sem a burocracia e os dispêndios decorrentes dessa empreitada. Esse instrumento é tomado do investigado mediante cominações, e constitui título executivo extrajudicial de competência da justiça do trabalho.

O artigo 13 da Lei 7.347 (BRASIL, 1985) - Lei da Ação Civil Pública (LACP) - dispõe que, nos casos de condenação ao pagamento de indenizações em dinheiro, este será revertido a um fundo gerido por um Conselho Federal ou por Conselhos Estaduais de que participarão necessariamente o Ministério Público e representantes da comunidade. Este fundo será destinado à reconstituição dos bens lesados pelo dano em questão.

Habitualmente, na seara trabalhista, os recursos provenientes dessas indenizações são revertidos ao Fundo de Amparo ao Trabalhador (FAT), assim como as multas advindas de Termos de Ajuste de Conduta firmados perante o Ministério Público do Trabalho.

Isso ocorre frente à total inadequação do chamado Fundo de Direitos Difusos (FDD), regulamentado pelo Decreto $\mathrm{n}$ - 1.306 (BRASIL, 1994), e criado para suprir a lacuna decorrente da previsão do art. 13 da LACP.

Conforme o parágrafo 10 do art. 10 da Lei 9.008 (BRASIL, 1995), o FDD tem por finalidade a reparação dos danos causados ao meio ambiente, ao consumidor, a bens e direitos de valor artístico, estético, histórico, turístico, paisagístico, por infração à ordem econômica e a outros interesses difusos e coletivos (ALMEIDA, 2010, p. 78). Percebe-se, pela análise do excerto, que o objetivo central do Fundo é arredio ao direito trabalhista, mostrando-se inadequado para a destinação dos recursos. 


\section{A inadequação da destinação de recursos obtidos pelo MPT ao Fundo de Amparo ao Trabalhador e} a sua utilização em ações de política pública social

Ocorre que o FAT também não se amolda integralmente ao fundo previsto na LACP, posto que não possui a participação do Ministério Público do Trabalho, nem mesmo tem o objetivo específico de reconstituir os danos causados aos direitos juslaborais.

Conforme definição conceitual dada pelo próprio art. 10 da Lei 7.998 (BRASIL, 1990), o Fundo de Amparo ao Trabalhador é um fundo contábil, de natureza financeira, vinculado ao Ministério do Trabalho e destinado ao custeio do Programa-SeguroDesemprego, ao pagamento do abono salarial e ao financiamento de programas de desenvolvimento econômico.

Assim, tem-se que o FAT possui objetivos específicos definidos em lei, e dentre eles não consta nenhum que atenda à finalidade de reparação dos danos eminentemente trabalhistas.

Como bem esclarece Rodrigo de Lacerda Carelli (2007, p. 42) em nenhum dos programas instituídos pelo Fundo de Amparo ao Trabalhador é exigida como contraprestação o respeito à legislação trabalhista, nem mesmo nos financiamentos realizados pelo BNDES, a partir de verbas do FAT, em favor das grandes empresas.

O BNDES recebe $40 \%$ das verbas do FAT para o financiamento de programas voltados ao desenvolvimento econômico (BRASIL, 2011). Frise-se que não há distinção entre as empresas que cumprem a legislação trabalhista e aquelas que causam danos, para fins de recebimento deste financiamento; o que, nas palavras de Marcos Antonio Ferreira Almeida (2010, p. 87), gera um verdadeiro contrassenso, pois possibilita um financiamento oficial das próprias práticas combatidas pelas ações coletivas que geraram aqueles recursos.

Sobre o tema, assevera o aludido autor (CARELLI, 2007, p. 43):

\footnotetext{
Desta forma, podemos chegar a uma fácil conclusão: Não temos o fundo da lei. Bem verdade que o parágrafo único ${ }^{5}$ do art. 13 da Lei da Ação Civil Pública dá uma alternativa até a criação do fundo previsto: a existência de uma conta corrente remunerada, na qual seriam depositados os valores oriundos das ações coletivas. Deve ser lembrado que já há anteprojeto na Procuradoria-Geral do Trabalho para a criação de Fundo decorrente da tutela coletiva realizada pelo Ministério Público do Trabalho, aprovado pelo Colégio de Procuradores do parquet laboral.

Desta forma, à primeira vista, até a espera da criação do fundo previsto na lei, somente haveria a alternativa de se realizar o depósito da indenização em conta corrente. Entretanto, essa pode não ser a interpretação mais justa.
}

\footnotetext{
Parágrafo renumerado pela Lei no 12.288/2010, a qual incluiu o parágrafo segundo no art. 13 da Lei
} $7347 / 1985$. 
Como se pode extrair da citação, já há anteprojeto na Procuradoria-Geral do Trabalho para a criação do Fundo previsto na lei. Do mesmo modo, o art. 26 do antigo anteprojeto do Código Brasileiro de Processos Coletivos (BRASIL, 2005) dispunha acerca da reparação dos danos por meio de obrigações específicas, destinadas à compensação pelo bem jurídico afetado, possibilitando ao juiz do trabalho direcionar os recursos decorrentes do provimento reparatório, independentemente de pedido do autor (ALMEIDA, 2010, p. 87).

De qualquer maneira, são soluções que dependem da atuação do poder legislativo, e que carecem da imediatividade necessária para conferir efetividade à reparação in natura das lesões coletivas trabalhistas.

Importante salientar que o art. 13 da LACP trata da destinação das condenações pecuniárias em sede de Ação Civil Pública, e em nenhum momento regulamenta o destino das multas cominatórias previstas nos Termos de Ajuste de Conduta firmados entre o MPT e os empregadores.

Em relação a estes, existe grande divergência sobre a natureza jurídica do instituto, havendo várias correntes doutrinárias, sendo duas delas as principais: a que defende sua natureza transacional (PEREIRA, 2010, p. 336), e a que classifica o TAC como negócio jurídico em sentido amplo (CARELLI, 2007, p. 42).

A transação é regulada pelos arts. 840 e ss. do Código Civil (BRASIL, 2002), o qual dispõe que o instituto existe com a finalidade de prevenir ou extinguir litígios, mediante concessões de ambas as partes, referentes a direitos patrimoniais de natureza privada.

Para os defensores da proibição da transação em sede coletiva, haveria a inexistência de concessão por parte do Ministério Público, já que os direitos são indisponíveis e irrenunciáveis. Entretanto, conforme esse entendimento, é cabível a negociação entre as partes acerca do tempo, modo e lugar do cumprimento das obrigações, objetivando a reconstituição do bem lesado, sendo esta a corrente adotada para o presente trabalho.

Como alternativa à lacuna legislativa, a própria Lei da Ação Civil Pública (LACP) previu em seu art. 13, parágrafo 10 (BRASIL, Lei 7.347, 1985), que o dinheiro seja remetido a uma conta corrente remunerada. Entretando, conforme dotrina do autor Rodrigo de Lacerda Carelli (2007, p. 42), esta não se mostra a solução mais justa e adequada, uma vez que a 
A inadequação da destinação de recursos obtidos pelo MPT ao Fundo de Amparo ao Trabalhador e a sua utilização em ações de política pública social

previsão foi criada para ser usada de maneira estritamente temporária, o que não seria possível no presente contexto.

Analisada as principais formas de obtenção de recursos pelo ente ministerial, bem como a inadequação do FAT e do FDD frente à previsão legal do art. 13 da Lei de Ação Civil Pública, cabe a análise das alternativas que o membro do MPT possui e sua convergência com as metas e princípios institucionais que o Ministério Público adquiriu com a vigência da Constituição de 1988.

\section{O MPT e a promoção de ações de política pública social por meio da destinação de recursos}

Cumpre salientar inicialmente, o papel do Ministério Público do Trabalho (MPT) como defensor da ordem jurídica, do regime democrático e dos interesses sociais e individuais indisponíveis, nos termos do art. 127 da Constituição Federal. Leia-se:

Art. 127. O Ministério Público é instituição permanente, essencial à função jurisdicional do Estado, incumbindo-Ihe a defesa da ordem jurídica, do regime democrático e dos interesses sociais e individuais indisponíveis. (BRASIL. Constituição da República Federativa do Brasil, 1988)

Conforme lição de Luiza Cristina Fonseca Frischensen (2000, p. 112), o Ministério Público só adquiriu a atribuição para a defesa dos interesses difusos e coletivos após a edição da lei 7.347/1985, deixando de ser mero braço do Estado, para se tornar verdadeiro advogado da sociedade.

Dentre as inúmeras áreas de atuação do órgão ministerial trabalhista, existem algumas que são consideradas prioritárias, constituindo metas institucionais, conforme ensinamento de Carlos Henrique Bezerra Leite (2010, p. 165-166):

O MPT tem priorizado algumas áreas de atuação institucional em defesa da ordem jurídico-trabalhista: a) erradicação do trabalho infantil e regularização do trabalho do adolescente [...]; b) combate a todas as formas de discriminação no trabalho [...]; c) erradicação do trabalho escravo ou forçado e regularização do trabalho indígena; d) regularização das relações de trabalho, por meio de audiências públicas [...] e a exigência constitucional do concurso público; e)defesa do meio ambiente do trabalho [...]. 
Tem-se, portanto, que por meio dos recursos obtidos pelas condenações em sede de Ações Civis Púlicas - ACPs e multas provenientes de Termos de Ajuste de Conduta - TACs, pode o MPT, desde que seja impossível a reparação específica da lesão, destinar o dinheiro arrecadado para a consecução de políticas públicas nas áreas tidas como prioritárias na atuação ministerial, desde que já haja um planejamento prévio realizado por parte do poder público, conforme será analisado na sequência.

É bastante evidente a eficiência com que a questão é tratada quando esse pagamento em dinheiro ao FAT é substituído por obrigações de fazer, não-fazer, entrega de coisa ou mesmo entrega de dinheiro a outros órgãos e instituições voltados à tutela de interesses afetos ao bem jurídico lesado, dentro da própria comunidade afetada, pois além do caráter pedagógico, já inerente ao dano moral coletivo, por exemplo, esta parcela também adquire caráter ressarcitório, próprio das indenizações individuais e que, no âmbito coletivo, atuam de forma bastante satisfatória.

Esse comportamento gera ações eficazes, auxiliando nas metas governamentais alçadas por meio de políticas públicas e nos objetivos adotados pela Carta Magna para a consecução de uma sociedade justa e solidária, com respeito aos valores sociais do trabalho.

Mauro Schiavi (2008, p. 307) defende que o valor dessa reparação possa ser direcionado aos próprios trabalhadores de determinada empresa, na modalidade de concessão de um benefício, como por exemplo a realização de um curso de reciclagem. Por seu turno, Xisto Tiago de Medeiros Neto (2007, p. 169) lista uma série de exemplos compatíveis com o aludido:

Seriam exemplos de tais obrigações pactuadas com o ofensor:

(a) promover e financiar campanha publicitária ou educativa;

(b) efetuar específica obra;

(c) adquirir e entregar bens a determinadas entidades públicas ou privadas (realizadoras de atividades de interesse público ou social), e que sejam úteis às suas iniciativas;

(d) executar certo projeto de cunho social.

Na visão de Raimundo Simão de Melo (2008, p. 114), procurando dar adequada aplicação à lei e aos valores das multas e condenações por danos genéricos, procuradores e juízes do trabalho têm sido criativos com relação à destinação desses valores não mais para 
o FAT, mas para outros órgãos públicos e entidades privadas, com a finalidade de reconstruir os bens lesados e beneficiar diretamente as vítimas dos danos.

Sobre a efetividade da reparação in natura em detrimento do pagamento pecuniário, aduz Mauro Schiavi (2008, p. 307):

De outro lado, pensamos que a reparação in natura do dano moral coletivo é mais efetiva que a pecuniária, podendo o Juiz, sempre que possível e necessário à efetiva reparação do dano, converter o pedido de indenização em pecúnia em reparação in natura.

Percebe-se pelo excerto acima que o autor defende a possibilidade de o juiz declarar de ofício a substituição da condenação pecuniária pela reparação in natura. Posicionamento diverso possui Xisto Tiago de Medeiros Neto (2007, p. 169), o qual prevê a possibilidade de acordo entre as partes - conciliação judicial, ao invés da conversão de ofício.

Para Xisto Tiago de Medeiros Neto (2007, p. 169), a convolação ou redirecionamento da parcela não pode ser objeto de requerimento direto na petição inicial da ação civil pública, ou mesmo vir a ser contemplada em sentença, de ofício, pelo órgão julgador, uma vez que, para ele, a lei é taxativa em relação ao encaminhamento da parcela ao fundo previsto no art. 13 da LACP.

Em contrapartida, valendo-se da autocomposição, a destinação desses recursos pode tomar os mais variados rumos. O Ministério Público do Trabalho, desde que tenha a anuência da outra parte, mesmo com a sentença já prolatada, poderá destinar esse dinheiro à consecução de ações passíveis de reparar danos coletivos e de promover políticas públicas.

A coisa julgada material, nesse caso, não impede que as partes resolvam destinar a parcela para outro programa, instituição ou fundo diverso daquele previsto em sentença. Trata-se de autocomposição com fim lícito, previsto no ordenamento jurídico por meio de suas regras e princípios, e benéfica a toda a sociedade envolvida direta ou indiretamente na lide coletiva.

Assim como ocorre nos processos de jurisdição voluntária, onde não incide a coisa julgada material (LOPES, 2006, p.159), havendo acordo entre as partes, não há que se falar no caso julgado, uma vez que este ponto não é controvertido no processo, sendo o efeito principal da sentença a própria condenação ao pagamento. 
Sobre a relação entre a coisa julgada e os efeitos do julgamento previsto em sentença, ensina Giuseppe Chiovenda (1998, p. 463) que "podem as partes renunciar aos efeitos do julgado, nunca, porém, pretender, seja por acordo, uma nova decisão sobre uma relação já decidida."

Em relação ao redirecionamento da parcela pelo próprio juiz do trabalho, mesmo após a sentença condenatória da Ação Civil Pública, pode ele, de ofício, encaminhar o dinheiro para o FAT, sem que isso configure julgamento extra-petita. Isso porque o FAT é fundo genérico em relação ao pedido principal da demanda, o que não desvirtua o pedido do autor.

De outro modo, o juiz não poderá, de ofício, destinar esse dinheiro a outra instituição, fundo ou programa, uma vez que essa atitude ofenderia a pretensão aduzida pelo requerente, pois, nessa última hipótese, tanto o pedido do autor, como a destinação dada pelo juiz carregariam uma carga antagônica de especificidade.

De fato, há no caso uma visão crítica em relação à coisa julgada que incide sobre o decisório. Isso acontece em decorrência do chamado efeito anexo da sentença, o qual pode ser definido como o efeito secundário, ou indireto, que é determinado pela lei como consequência imediata e automática de alguns dos efeitos principais (LIEBMAN, 2003, p. 153).

Assim, há no caso liberdade para as partes na destinação da parcela condenatória, bem como a faculdade para o juiz de destiná-la ou não ao FAT, uma vez que a coisa julgada, como qualidade da sentença (THEODORO JUNIOR, 2004, p. 479), incidirá apenas em seu efeito principal - a condenação - e não em seu efeito anexo - a destinação dos recursos advindos de seu pagamento, o qual pode ser direcionado para a consecução de políticas públicas por meio da atuação do MPT.

Enfim, adentrando no tema referente aos requisitos da convolação dessa parcela, conforme ensinamento de Xisto Tiago de Medeiros Neto (2007, p. 169), para que se possa substituir o pagamento ao FAT, é necessário observar dois aspectos, quais sejam: a pertinência entre o direito lesado e a obrigação acordada, bem como o respeito aos princípios da proporcionalidade e razoabilidade quanto ao valor pecuniário que seria pago e o dispêndio decorrente da reparação in natura do dano. 


\section{A inadequação da destinação de recursos obtidos pelo MPT ao Fundo de Amparo ao Trabalhador e}

a sua utilização em ações de política pública social

Dessa maneira, o que se impõe é que as obrigações determinadas contribuam, direta ou indiretamente, para a proteção dos bens jurídicos lesados, na própria comunidade onde se encontram as vítimas dos danos, gerando a efetividade dos princípios constitucionais sociais, os quais foram, em regra, planejados pelo Estado e tendo no MPT um agente garantidor de sua plena execução.

Em doutrina relativamente diversa, o supra referido autor Rodrigo de Lacerda Carelli (2007, p. 43/44) menciona a possibilidade de reconstituição dos bens lesados em sentido amplo, ou seja, se impossível a destinação da indenização diretamente para a reconstituição dos bens especificamente lesados, pode-se proteger os direitos fundamentais do trabalho, objetos de tutela da ordem jurídica e do MPT, de forma genérica.

Faz-se imprescindível ressaltar a elaboração do Enunciado no 12 da 1a Jornada de Direito Material e Processual na Justiça do Trabalho, realizada em Brasília, no ano de 2007, a qual resultou na seguinte consolidação por parte da Associação Nacional dos Magistrados da Justiça do Trabalho (ANAMATRA):

12. AÇÕES CIVIS PÚBLICAS. TRABALHO ESCRAVO. REVERSÃO DA CONDENAÇÃO ÀS COMUNIDADES LESADAS.

Ações civis públicas em que se discute o tema do trabalho escravo. Existência de espaço para que o magistrado reverta os montantes condenatórios às comunidades diretamente lesadas, por via de benfeitorias sociais tais como a construção de escolas, postos de saúde e áreas de lazer. Prática que não malfere o artigo 13 da Lei $7.347 / 85$, que deve ser interpretado à luz dos princípios constitucionais fundamentais, de modo a viabilizar a promoção de políticas públicas de inclusão dos que estão à margem, que sejam capazes de romper o círculo vicioso de alienação e opressão que conduz o trabalhador brasileiro a conviver com a mácula do labor degradante. Possibilidade de edificação de uma Justiça do Trabalho ainda mais democrática e despida de dogmas, na qual a responsabilidade para com a construção da sociedade livre, justa e solidária delineada na Constituição seja um compromisso palpável e inarredável (ALMEIDA, 2010, p. 100).

Dessa maneira, considerando-se legítimo o estabelecimento de prazos, condições e modos para o cumprimento das obrigações previstas no TAC ou na execução da condenação prevista na $L A C P$, do mesmo modo a execução de políticas públicas pelo órgão ministerial se mostra medida válida. Outrossim, uma vez que o MPT possui a legitimidade para agir, mas não a titularidade dos direitos tutelados, os quais são de toda a sociedade ou de uma determinada coletividade (CARELLI, 2007, p. 42), é necessário cautela na destinação do dinheiro auferido, bem como respeito ao ordenamento jurídico e seus princípios basilares. 
Tem-se, portanto, que o interesse da comunidade lesada está no restabelecimento do estado jurídico anterior aos danos sofridos, para que estes sejam reparados em sua integralidade, e não que esses direitos sejam convertidos em pecúnia e entregues ao FAT. Nesse sentido, a doutrina de Rodrigo de Lacerda Carelli (2007, p. 43):

Não há, então, que se ver como ilegal a possibilidade de utilização da indenização em pecúnia para um modo mais efetivo de recomposição da ordem jurídica, se o membro vislumbrar a possibilidade de melhor utilização da verba, por meio de um instrumento ou atividade mais útil para a reconstituição do bem da vida. Ainda que os beneficiados pela recomposição prevista não sejam os mesmos que foram diretamente lesionados pela atividade ilícita, eis que, por natureza, a tutela coletiva pretende reconstituir a ordem jurídica, e não diretamente indenizar os trabalhadores lesados.

Como já mencionado, políticas públicas são obrigação do Estado, especialmente no que se refere ao seu planejamento, sendo nessa seara, intransferível. Porém, o Ministério Público também é legitimado a executá-las por meio de ações de políticas públicas, já que é órgão estatal, essencial à justiça, defensor do ordenamento jurídico e dos interesses sociais, podendo, com os recursos de que dispõe, realizar medidas aptas a alcançar melhorias efetivas em prol do trabalhador.

Não é função precípua do MPT elaborar e planejar as políticas públicas nacionais, mas em relação à sua execução, o órgão ministerial pode ter participação efetiva. Ademais, caso fosse necessário classificar o Ministério Público como integrante de algum dos poderes nacionais, este certamente estaria insculpido dentro do Poder Executivo, o que reforça a ideia de legitimidade do parquet para a promoção das políticas públicas previstas na Constituição Federal por meio da destinação dos recursos.

Partindo-se da premissa que a execução das políticas públicas é atribuição do Estado, ampliativamente considerado, não há como afastar a atuação do MPT neste âmbito, já que enquanto à Administração Estatal cabe o planejamento das metas institucionais, sua efetiva consecução abrange todos os demais campos de atuação do ente nacional.

Por meio dessa atuação efetiva do órgão ministerial trabalhista, verifica-se o respeito aos direitos insculpidos nos arts. 50, incs. V, X da Constituição da República Federativa do Brasil (BRASIL, 1988) e arts. 186 e 927 do Código Civil (BRASIL, 2002), aplicados subsidiariamente ao Direito do Trabalho por força do art. 8․, parágrafo único da CLT (BRASIL, 1943). Referida legitimação pode ser considerada anômala perante a divisão de funções 
A inadequação da destinação de recursos obtidos pelo MPT ao Fundo de Amparo ao Trabalhador e a sua utilização em ações de política pública social

existente no ordenamento jurídico pátrio, porém não inexistente, uma vez que o papel próativo do órgão ministerial ganha forças a cada obrigação pactuada em defesa dos direitos dos trabalhadores nacionais.

Assim, imperioso ressaltar que o MPT não tem sua atuação vinculada em relação ao encaminhamento dos recursos ao FAT, podendo ser importante agente das transformações sociais, utilizando-se dessa prerrogativa para o bem coletivo, em respeito aos princípios e valores previstos na Carta Constitucional.

Trata-se de reparação muito mais relevante para a comunidade local quando as indenizações e multas advindas da violação aos direitos juslaborais são destinadas à melhoria da qualidade de vida das próprias vítimas, e não a um fundo nacional de atuação genérica.

Cabe aos operadores do direito exercerem a hermenêutica constitucional de modo a conferir efetividade aos direitos dos cidadãos, a fim de que suas garantias não se tornem letra morta diante das mazelas sociais e, principalmente, para que a Constituição da República Federativa do Brasil cumpra seu papel na promoção do verdadeiro sentido de justiça.

\section{Conclusão}

O presente trabalho teve como foco a destinação dos recursos provenientes de condenações judiciais em sede de Ação Civil Pública e multas advindas de Termos de Ajuste de Conduta, pelo Ministério Público do Trabalho, para a consecução de políticas públicas sociais que auxiliem nas metas governamentais e nos objetivos da República, em face da inadequação da solução comumente utilizada em sede trabalhista, qual seja a destinação dos recursos ao Fundo de Amparo ao Trabalhador.

As formas de obtenção de recursos pelo órgão ministerial são, na realidade, instrumentos de atuação do parquet para a tutela dos interesses difusos, coletivos e individuais homogêneos.

Posteriormente, em análise crítica ao disposto no art. 13 da Lei da Ação Civil Pública, pôde-se observar que o Fundo de Direitos Difusos não é voltado para a seara juslaboral, motivo pelo qual se convencionou destinar esses recursos ao Fundo de Amparo ao Trabalhador. 
Ocorre que o FAT também não se amolda ao texto legal, havendo a necessidade de se encontrar soluções criativas e eficientes para a tutela dos interesses metaindividuais, com a consequente promoção de políticas públicas sociais previstas constitucionalmente.

Políticas públicas são programas de planejamento estatal que visam a destinar de maneira eficiente os recursos a disposição do Estado para a consecução das metas constitucionalmente previstas.

A legitimidade para o planejamento das políticas públicas nacionais é, sem dúvida, do ente governamental. Entretanto, o Ministério Público do Trabalho pode ter papel efetivo na execução dessas medidas, uma vez que, dispondo dos recursos necessários, tem a opção de vertê-los à consecução de medidas que garantam a dignidade dos trabalhadores, especialmente no que concerne às suas metas institucionais.

Em relação às condenações judiciais, tem-se que o juiz do trabalho pode destinar esse dinheiro diretamente ao FAT, posto que é fundo genérico em relação ao pedido do autor. Já se houver acordo entre as partes, independentemente de haver trânsito em julgado, uma vez presente o efeito anexo da sentença, esses recursos podem tomar os mais variados rumos, constituindo solução mais justa ao verdadeiro sentido de reparação.

Essa atuação diferenciada do órgão ministerial já tomou corpo em praticamente todo o território nacional, havendo jurisprudência e termos de compromisso firmados com as mais variadas espécies de direitos e garantias dos trabalhadores sendo tutelados de forma efetiva.

Assim, temos que todo dano merece uma reparação justa e, preferencialmente, passível de reverter a situação criada ao seu status quo ante, evitando-se, assim, a transformação maciça de todos os direitos em pecúnia, o que põe fim à ideia de justiça e verdadeira reparação.

\section{Referências}

ALMEIDA, Marco Antonio Ferreira. A efetividade da reparação do dano moral coletivo na justiça do trabalho. Revista do Ministério Público do Trabalho, v. 20, n. 39, mar, 2010.

ASSMAN, Hugo. Carta a Santo Agostinho. o Estado de S. Paulo, caderno Cultura, 28-10-1995, p. D-8, apud BUCCI, Maria Paula Dallari, 2002. 
A inadequação da destinação de recursos obtidos pelo MPT ao Fundo de Amparo ao Trabalhador e a sua utilização em ações de política pública social

BRASIL. Anteprojeto do Código Brasileiro de Processos Coletivos. Disponível em:<http://www.jfce.jus.br/internet/esmafe/materialDidatico/documentos/direitoSociedad elnformacional/anteprojetoProcessoColetivo-FranciscoWildo.pdf> Acesso em: 06 abr. 2011.

Constituição (1988). Constituição da República Federativa do Brasil. VadeMecum Compacto. São Paulo: Editora Saraiva, 2011.

. Código Civil. VadeMecum Compacto. São Paulo: Editora Saraiva, 2011.

. Código de Processo Civil. VadeMecum Compacto. São Paulo: Editora Saraiva, 2011.

Consolidação das Leis do Trabalho. Decreto-Lei no 5.452, de 1 de maio de 1943. Aprova a Consolidação das Leis do Trabalho. VadeMecum Compacto. São Paulo: Editora Saraiva, 2011.

. Decreto no 1.306, de 9 de novembro de 1994. Regulamenta o Fundo de Defesa de Direitos Difusos, de que tratam os arts. 13 e 20 da Lei no 7.347, de 24 de julho de 1985, seu conselho gestor e dá outras providências. Disponível em:

<http://www.planalto.gov.br/ccivil_03/decreto/1990-1994/D1306.htm> Acesso em: 16 abr. 2011.

. Lei da Ação Civil Pública. Lei no 7.347, de 24 de julho de 1985. VadeMecum Compacto. São Paulo: Editora Saraiva, 2011.

. Lei no 7.998, de 11 de janeiro de 1990. Regula o Programa do Seguro-Desemprego, o Abono Salarial, institui o Fundo de Amparo ao Trabalhador (FAT), e dá outras providências. Disponível em: <http://www.planalto.gov.br/ccivil_03/Leis/L7998.htm> Acesso em: 14 abr. 2011.

. Lei no 9.008, de 21 de março de 1995. Cria, na estrutura organizacional do Ministério da Justiça, o Conselho Federal de que trata o art. 13 da Lei no 7.347, de 24 de julho de 1985, altera os arts. 4으, 39, 82, 91 e 98 da Lei no 8.078, de 11 de setembro de 1990, e dá outras providências. Disponível em:

<http://www.planalto.gov.br/ccivil_03/Leis/L9008.htm> Acesso em: 16 abr. 2011.

. Ministério do Trabalho e Emprego. Página oficial do Fundo de Amparo ao Trabalhador. Disponível em: <http://www.mte.gov.br/fat/default.asp> Acesso em: 05 abr. 2011.

BUCCI, Maria Paula Dallari. Direito Administrativo e Políticas Públicas. São Paulo: Saraiva, 2002. 
CARELLI, Rodrigo de Lacerda. Transação na AçãoCivil Pública e na execução do Termo de Compromisso de Ajustamento de Conduta e a reconstituição dos bens lesados. Revista do Ministério Público Do Trabalho, v. 17, n. 33, mar, 2007.

CHIOVENDA, Giuseppe. Instituições de Direito Processual Civil. Tradução: Paolo Capitanio. 1. ed. Campinas: Editora Bookseller, 1998.

FRISCHEISEN, Luiza Cristina Fonseca. Políticas Públicas: a responsabilidade do administrador e o ministério público. São Paulo: Editora Max Limonad, 2000.

LEITE, Carlos Henrique Bezerra. Curso de Direito Processual do Trabalho. 8. ed. São Paulo: LTr, 2010.

LIEBMAN, Enrico Tullio. Manual de Direito Processual Civil. Tocantins: Intelectus Editora, 2003. v. 1.

LOPES, João Batista. Curso de Direito Processual Civil. São Paulo: Atlas S.A, 2006. v. 2.

MEDEIROS NETO, Xisto Tiago de. Dano Moral Coletivo. 2. ed. São Paulo: LTr, 2007.

MELO, Raimundo Simão de. Ação Civil Pública na Justiça do Trabalho. 3. ed. São Paulo: LTr, 2008.

PEREIRA, Luis Fabiano. Natureza Jurídica Transacional do Compromisso de Ajustamento de Conduta firmado perante o Ministério Público. Revista do Ministério Público do Trabalho, v. 20, n. 39, mar. 2010.

SCHIAVI, Mauro. Aspectos polêmicos e atuais do dano moral coletivo decorrente da relação de trabalho. Revista da Escola Paulista de Direito, Campinas, v. 4. mar./abr. 2008.

THEODORO JUNIOR, Humberto. Curso de Processo Civil. v. 2. 41. ed. Rio de Janeiro: Editora Forense, 2004. 